\title{
MEF2C mediates the activation induced cell death (AICD) of macrophages
}

\author{
Wenxia Fu ${ }^{1}$, Jinxue Wei ${ }^{1}$, Jun $\mathrm{Gu}^{1}$ \\ ${ }^{I}$ National Key Laboratory of Protein Engineering and Plant Genetic Engineering, College of Life Science, Peking University, Beijing \\ 100871, China
}

Activation-induced cell death (AICD) of immune cells is widely believed to be crucial for the regulation of immune responses. Although macrophage apoptosis has been observed under a variety of pathological conditions, questions as to whether there is AICD of macrophages and how macrophage life span is regulated have not been well addressed. AICD in macrophages requires two signals. One is cell activation triggered by LPS or other bacterial components. The other is an event that exists in AICD-susceptible (primed) but not unsusceptible (resting) macrophages. Here we show that RAW264.7 cell is susceptible to LPS stimulation when it is primed with Salmonella typhimurium, type 5 adenovirus (Ad5) or IFN- $\gamma$. We found that the stability of the transcription factor MEF2C is increased in primed RAW264.7 cell. Transfection of a dominant negative form of MEF2C protects primed macrophage from cell death triggered by LPS. Our data demonstrate that the increase of MEF2C protein stability is a key factor in the AICD of macrophage.

Cell Research (2006) 16:559-565. doi:10.1038/sj.cr.7310073; published online 15 June 2006

Keywords: MEF2C, AICD, macrophage

\section{Introduction}

Apoptosis of immune cells including macrophages has been found to occur in inflammatory diseases [1-5]. Apoptosis of activated macrophages may serve to restrict and focus the immune response, but it may also reduce the host defenses against infectious pathogens or contribute to immune suppression. Although our understanding of apoptosis has greatly improved in recent years, apoptosis of activated macrophages has been ill addressed in comparison with the apoptosis of lymphocytes [6-8]. In immune cells, apoptosis usually occurs by a particular way called activation induced cell death (AICD) [6-8].

Macrophages are long-lived cells when they are in a resting stage. It has been suggested that the lifespan of macrophages in inflammation sites was extended by survival factors such as apoptosis inhibitor and nerve growth

Correspondence: Jun Gu

Tel: 86-10-62756174; Fax: 86-10-62756174;

E-mail: gj@pku.edu.cn

Received 19 Jul 2005; revised 20 Nov 2005; accepted 28 Nov 2005; published online 15 Jun 2006 factor secreted by macrophages or other cells $[9,10]$. On the other hand, macrophage death has been observed in many inflammatory diseases [1-5]. Macrophage death could result from different causes. Phagocytosis of infected microorganisms by macrophages is part of the host response to infection. However, some virulent bacteria are able to evade killing by macrophages and actually induce macrophage death. It is known that the mechanism of macrophage death induced by different pathogens varies [11-14]. Bacterial endotoxin (lipopolysaccharide; LPS) is a complex glycolipid found in the outer membrane of all gram-negative bacteria, and is believed to play a crucial role in induced cellular responses to gram-negative bacteria. The effect of LPS on macrophage cell death has been widely studied. LPS can induce cell death of a number of macrophages that have been primed by exposure to viruses, such as bovine herpes virus- $1[15,16]$, or cytokines, such as interferon- $\gamma$ (IFN- $\gamma$ ). IFN- $\gamma$ is induced in virusstimulated cells, which could promote macrophage cell death [16-18]. It is also known that macrophages primed with proinflammatory cytokines holds the ability to eliminate highly resistant microorganisms [19]. However, IFN- $\gamma$ primed macrophages could be dangerous 
because activated macrophages after priming could damage the local tissues when they are out of control.

IFN- $\gamma$ is clearly not the only factor that can prime macrophages to become sensitive to LPS-induced cell killing $[17,20]$. For example, LPS was reported to cause cell death of conA or IFN- $\gamma$ primed macrophages and to enhance cell death induced by the Yersinia baccillus [17, 20, 21]. Intriguingly, it was found that zVAD and boc-D, pan-caspase inhibitors that inhibit apoptosis in many different cells, not only had no inhibitory effect on LPS-induced apoptosis in INF- $\gamma$ primed macrophages but also by themselves induced susceptibility to LPS-induced cell death in macrophages [22]. As zVAD treatment can prime macrophages for LPSinduced cell death, a previous study by Kim et al. utilized this model system to investigate the underlying molecular mechanisms [22]. They showed that induction of the orphan nuclear receptor Nur77 is a key event. Induction of Nur77 was found to correlate with macrophage AICD; and Nur77 deficient macrophages were insensitive to zVAD priming. Further analysis implicated a critical role of the MEF family of transcription factors, which are involved in apoptosis in several cell lines including macrophages [22, $28,29]$. Kim et al. showed that zVAD treatment increased the protein stability of MEFs, which could then bind to the Nur77 promoter and are presumably required for induction of Nur77 during macrophage death [22]. The study by Kim et al. strongly suggests that cell death in zVAD primed macrophages involves the MEF/Nur77 pathway; however, it remains to be determined whether a similar mechanism also applies to macrophage death under pathological conditions. We thus explored this issue and report here that the transcription factor MEF2C is a key player mediating LPS-induced cell death in macrophages primed either by pathogens or by INF- $\gamma$.

\section{Materials and Methods}

\section{Cell culture and treatments}

RAW 264.7 cells were maintained in RPMI1640 medium supplemented with $10 \%$ FBS. For the induction of cell death, $5 \times 10^{5}$ cells/well were seeded into 12 -well plate and cultured at $37^{\circ} \mathrm{C}$ for $24 \mathrm{~h}$ in the presence or absence of other reagents. Cell viability was analyzed under a microscope, or determined using propidium iodide (PI) exclusion $24 \mathrm{~h}$ after LPS addition.

\section{Total cell lysate preparation and western blot analysis}

Cells were lysed using the lysis buffer (20mM Tris, $\mathrm{pH} 7.5,150$ $\mathrm{mM} \mathrm{NaCl}, 10 \%$ glycerol, $1 \%$ Triton X-100, $1 \mathrm{mM} \mathrm{Na3VO} 4,2 \mathrm{mM}$ EDTA, $10 \mu \mathrm{g} / \mathrm{ml}$ aprotinin, $10 \mu \mathrm{g} / \mathrm{ml}$ leupeptin, $1 \mathrm{mM}$ phenylmethylsulfonyl fluoride). Lysate was centrifuged $20000 \times \mathrm{g}, 10 \mathrm{~min}$ at 4 ${ }^{\circ} \mathrm{C}$. The supernatant was collected as total cellular proteins. For the preparation of nuclear protein, cells were resuspended in Buffer A (10 mM HEPES-KOH, $1.5 \mathrm{mM} \mathrm{MgCl}, 10 \mathrm{mM} \mathrm{KCl}, 0.5 \mathrm{mM}$ DTT, 0.2 mM PMSF, 0.5 mM Leupeptin, $\mathrm{pH} 7.9$ ) and incubated on ice for $10 \mathrm{~min}$. Lysate was centrifuged at $5000 \times \mathrm{g}$ for $10 \mathrm{~min}$ at 4 ${ }^{\circ} \mathrm{C}$. The pellet was subsequently resuspended in Buffer B $(20 \mathrm{mM}$ HEPES-KOH, 25\% Glycerol, $1.5 \mathrm{mM} \mathrm{MgCl}$, $420 \mathrm{mM} \mathrm{NaCl}, 0.2$ mM EDTA, 0.5 mM DTT, 0.2mM PMSF, 0.5mM Leupeptin, $\mathrm{pH}$ 7.9) and incubated on ice for $30 \mathrm{~min}$. The supernatant as nuclear proteins were collected by centrifugation at $10000 \times \mathrm{g}$ for $10 \mathrm{~min}$ at $4{ }^{\circ} \mathrm{C}$. Antibody for MEF2C were purchased from Santa Cruz Biotechnology, Inc. and western blot assay was performed by standard protocol.

\section{Electrophoretic mobility shift assay (EMSA)}

Nuclear exact of RAW264.7 cell were incubated with the doublestranded, 32P-labeled oligonucleotide probe containing an MEF2 binding site, as previously described [23].

\section{RNase protection assay}

Total RNA was isolated using TRIzol (Life Technologies, Gaithersburg, MS). RiboQuant ${ }^{\circledR}$ Multi-Probe RNase Protection Assay System (PharMingen) was used for RPA. Briefly, 32P-Labeled antisense riboprobes for MEF2C corresponding to the sequence 404-695 were generated from the linearized plasmid using T7 RNA polymerase. Labeled probe and $10 \mu \mathrm{g}$ of RNA were incubated in hybridization buffer overnight at $56{ }^{\circ} \mathrm{C}$ before digestion with $\mathrm{T} 1 \mathrm{RNase}$ for $45 \mathrm{~min}$ at $30{ }^{\circ} \mathrm{C}$. Protected fragments were dissolved in RNA loading buffer and subjected to electrophoresis on a $4.75 \%$ polyacrylamide-urea gel. Gels were dried on Whatman filter paper and then exposed to autoradiograph film overnight. Each template set includes probes for GAPDH, which serve as internal standard to verify equal loading between sample lanes.

\section{Crystal violet assay}

After incubation, cells were fixed by addition of $1 \%$ glutaraldehyde. They were washed, dried, and stained with crystal violet $(0.5 \%$; in methanol:water, $20: 80 \%)$. Unfixed crystal violet was removed by washing four times, and then the plates were re-dried. Finally, the adherent crystal violet in each well was solubilized with $1 \%$ SDS, and the absorbance units were simultaneously determined (96-well microtiter plate reader; $600-\mathrm{nm}$ filter; $\mathrm{n}=3$ ). To validate the crystal violet method for assessing cell numbers, a 96-well plate was seeded with serial cell dilutions ( $\mathrm{n}=6$ for each concentration). The plates were cultured for $24 \mathrm{~h}$, and then crystal violet staining was performed.

\section{Results}

\section{LPS induces cell death in primed macrophages}

It has been documented that stimulation of resting macrophages by bacterial components such as LPS does not cause cell death. However, LPS activation of macrophages primed with con A, IFN- $\gamma$, IFN- $\gamma$, bovine viral diarrhea virus, or herpesvirus- 1 causes macrophage apoptosis [15$18,20]$. We examined the effect of LPS on the viability of macrophages primed with Salmonella typhimurium (MOI of 5:1) or type 5 adenovirus (Ad5) (MOI of 10:1). Treatment of macrophages with bacteria or virus did not affect the viability of the cells though some morphological changes were observed (Figure 1A, top panels). Stimula- 
A

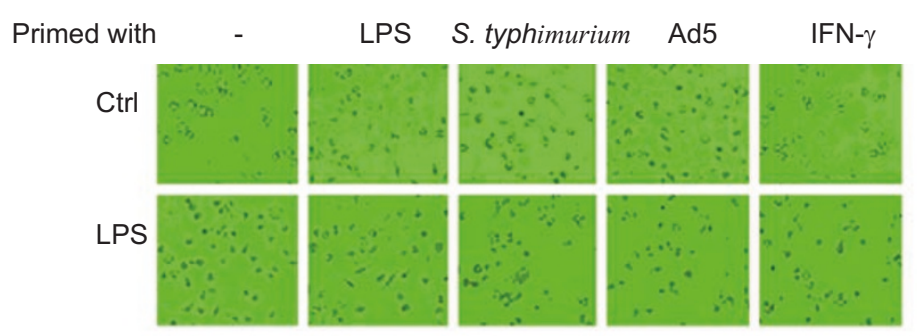

B

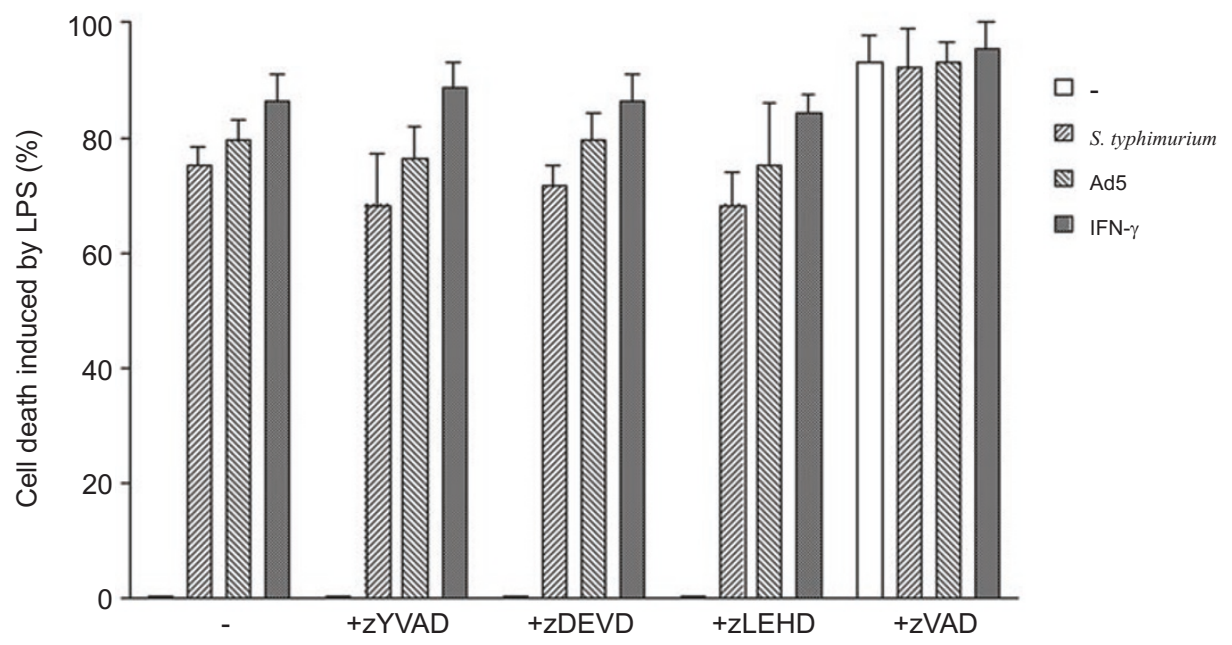

Figure 1 Viability of LPS stimulated mouse peritoneal macrophages primed with different reagents in the presence or absence of different caspase inhibitors. Peritoneal macrophages were treated with nothing (-), LPS (10ng/ml), S. typhimurium (MOI 5:1), Ad5(MOI 10:1), or IFN- $\gamma(5 \mathrm{U} / \mathrm{ml})$ for $24 \mathrm{~h}$. LPS $(10 \mathrm{ng} / \mathrm{ml})$ stimulation was applied after the cells were washed three times with PBS and changed into fresh medium. (A) Cell viability was analyzed under a microscope $24 \mathrm{~h}$ after LPS addition. (B) Caspase inhibitors $(50 \mu \mathrm{M})$ were added 30 min before LPS stimulation. The cell viability was determined by crystal violet staining of adherent cells. The percentage of cell death was calculated by referencing a standard curve with different concentrations of cells. All results are means of triplicate samples.

tion with LPS for $24 \mathrm{~h}$ induced the death of these primed macrophages (Figure 1A, lower panels and 1B). As controls, cells were primed with IFN- $\gamma$ or LPS. Subsequent LPS challenge induced cell death in IFN- $\gamma$ primed cultures, but not in LPS-primed cultures. Treatment with vZAD and other caspase inhibitors including zYVAD, zDEVD and zLEHD did not protect cell death. On the contrary, zVAD enhance the cell death slightly (Figure1B). Consistent with earlier reports [22], we also found that zVAD treatment could prime macrophages for subsequent cell death induced by LPS (Figure 1B).

\section{MEF2C is activated in primed macrophages}

It is clear that macrophages undergo many different cellular changes in response to different stimuli such as $S$. $t y$ phimurium, adenovirus, IFN- $\gamma$, or zVAD. As shown in Figure 1 , the morphological changes are readily distinguishable; cell spreading was seen in S. typhimurium or adenovirus treated cells but there was no apparent change in IFN- $\gamma$ treated cells.
Treatment of macrophages with zVAD did not cause any morphological change of these cells [20]. We examined the expression of a number of different genes including p 53 and $\mathrm{Rb}$ that may be related to cell death and cell differentiation in RAW264.7 cells. We found that the level of one gene product, MEF2C, was dramatically increased in cells that were primed with $S$. typhimurium, adenovirus, or IFN- $\gamma$ (Figure $2 \mathrm{~A})$. Treatment of the cells with zVAD also dramatically increased MEF2C protein level (Figure 2A). LPS stimulation did not have any effect on MEF2C expression. The increase of $\mathrm{MEF} 2 \mathrm{C}$ protein was correlated with increased MEF2 activity, as measured by electrophoretic mobility shift assay (Figure 2B). Since the quantity of MEF2C protein was dramatically increased in the cells that are sensitive to LPS-induced cell death, MEF2C protein may be a hallmark of the AICD-susceptible state in macrophages.

\section{MEF2C is increased by protein stabilization}

$\mathrm{MEF} 2 \mathrm{C}$ is a transcription factor that was originally 
identified as a gene specifically expressed in differentiated muscle and brain. It has been reported that its mRNA is also expressed in macrophages [24]. Although the mRNA of MEF2C in macrophages was easily detectable [24], the protein level was barely detectable at rest stage (Figure $2 \mathrm{~A}$ ), suggesting either the MEF2C translation rate is very low or the MEF2C protein is unstable in resting macrophages. We measured MEF2C mRNA from resting and AICD-susceptible cells induced by different stimuli. As shown in Figure 3A, the MEF2C mRNA level was about the same in AICD-susceptible and -unsusceptible cells, indicating that the up-regulation of MEF2C protein in AICD-susceptible cells was not controlled by transcription and mRNA stability. To determine whether MEF2C protein was expressed and then quickly degraded, we treated cells with the proteasome inhibitor, MG132. A rapid increase of MEF2C protein was found (Figure 3B and $3 \mathrm{C}$ ), indicating that protein stability is a key factor controlling MEF2C protein level in macrophages. A rapid increase of MEF2C protein was also observed in zVADtreated cells (Figure 3C). The kinetics of MEF2C protein induction was about the same in cells treated with MG132 and zVAD (Figure 3C).

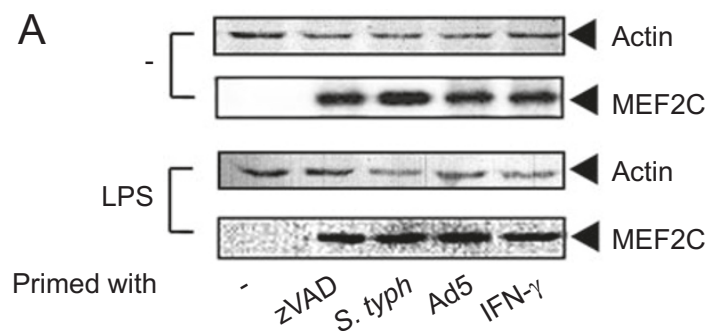

B

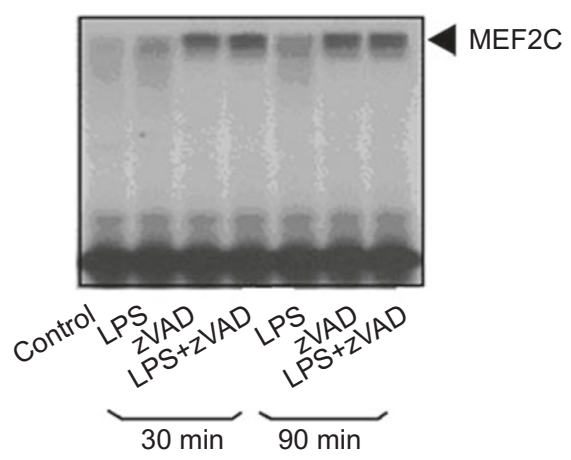

Figure 2 Increase of MEF2C protein and DNA binding activity in primed and zVAD treated cells. (A) RAW264.7 cells were primed as described in Figure 1 or treated with $\operatorname{zVAD}(20 \mu \mathrm{M})$ for $2 \mathrm{~h}$. Cells were left untreated or treated with LPS for $24 \mathrm{~h}$, then lysed and MEF2C protein was analyzed by Western blotting with antiMEF2C antibody. (B) RAW264.7 cells were treated with LPS, zVAD respectively or LPS+zVAD for different time, then MEF2 activity was measured by EMSA.
A

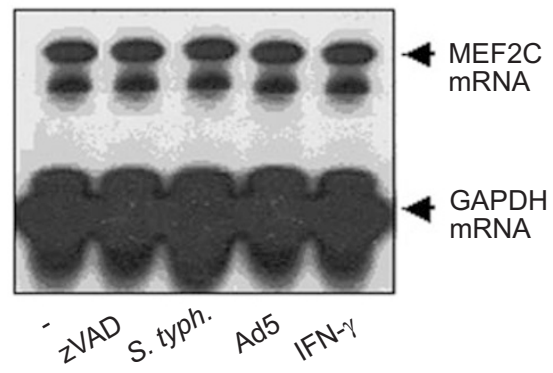

B

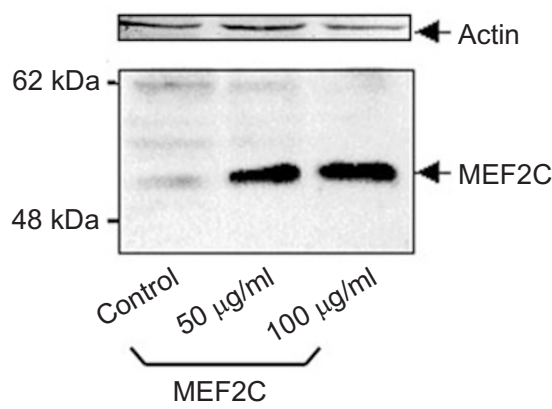

C
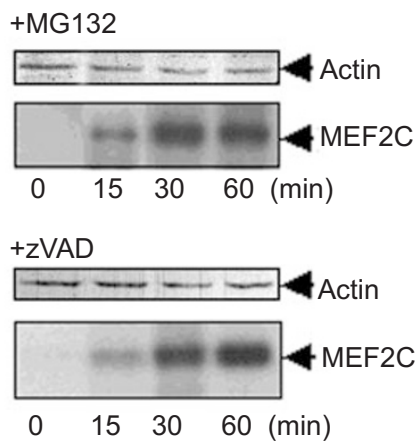

Figure $3 \mathrm{MEF} 2 \mathrm{C}$ was increased by protein stabilization. (A) MEF2C mRNA was detected by RNase protection in RAW264.7 cells that were in resting or induced into AICD-susceptible state by zVAD, S. typhimurium, Ad5, or IFN- $\gamma$. (B) MEF2C protein was detected by Western blotting in RAW cells treated with different doses of MG132 for 30 min. (C) MEF2C protein was detected by Western blotting in the RAW cells treated with $50 \mu \mathrm{M}$ MG132 or $20 \mu \mathrm{M}$ zVAD for different time.

MEF2 activity is required for LPS-induced macrophage death

To examine whether increased level of MEF2C activity is required for macrophages to be susceptible to LPS-induced killing, we made a stable line from RAW 264.7 cells in which a dominant negative form of MEF2C (MEF2CR24L)[25] was expressed. As shown in Fig. 4, the MEF2CR24L transfected cells were resistant to AICD induced by LPS in comparison with vector-transfected cells. Thus, MEF2 activity is required for RAW cells to develop into the AICD-susceptible state. 


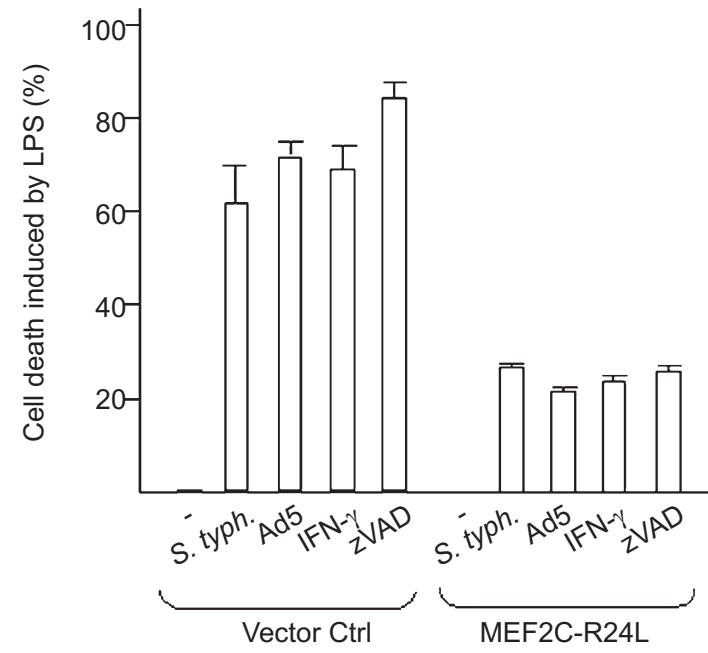

Figure 4 Expression of dominant negative MEF2C inhibits LPSinduced cell death in AICD-susceptible RAW cells. RAW cells were stably transfected with MEF2C-R24L or empty vector. The cells were induced into AICD-susceptible state and then stimulated with LPS. Cell viability was determined $24 \mathrm{~h}$ after LPS addition using propidium iodide(PI) exclusion.

\section{Discussion}

MEF2C is a member of the MEF2 transcription factor family. Although MEF2C is known as a myogenic factor in muscle, it was also found in brain and macrophage [24, $26,27]$. It has been shown to be involved in neuron and macrophage apoptosis [22, 28, 29]. A previous study by Kim et al. showed that LPS induces caspase independent cell death in zVAD primed macrophages, and that an important functional consequence of zVAD priming is the stabilization of MEF transcription factors (Figure1B) [22]. We show here that macrophages primed with Salmonella typhimurium, type 5 adenovirus (Ad5) or IFN- $\gamma$ are susceptible to LPS treatment. Priming of RAW264.7 cell alone or LPS treatment alone does not result in cell death (Figure 1 and 4). Cell death only occurs under the combined conditions of priming and LPS. The administration of LPS is given $24 \mathrm{~h}$ ( $2 \mathrm{~h}$ for $\mathrm{zVAD}$ ) after cells are primed (Figure 1). The priming time of $S$. typhimurium and adenovirus can be as short as $12 \mathrm{~h}$ (data not shown). IFN- $\gamma$ can be added at the same time as LPS to induce cell killing. These data are consistent with results reported by others using IFN or virus primed cells [15-18, 20, 21].

MEF2C seems to be a hallmark of the AICD-susceptible state of macrophages. We have tested the products of many genes that could be related to AICD (data not shown). MEF2C shows a predominant change in its activity and protein level when RAW264.7 cells are primed with either zVAD, Salmonella typhimurium, type 5 adenovirus (Ad5) or IFN- $\gamma$ (Figure 2). LPS alone has little effect on MEF2C protein level or activity. The mRNA of MEF2C remains unchanged during priming (Figure 3A). The increase of $\mathrm{MEF} 2 \mathrm{C}$ protein and its activity result from the increase of protein stability (Figure 3B and 3C). These results are consistent with others [22]. Therefore, protein stability is a key factor controlling MEF2C protein level in macrophages primed with pathogenic components. Protein stability could be regulated by proteasome and/or caspase-like activities. It is unlikely that the increase of MEF2C protein level by zVAD treatment is due to the regulation by a caspase-like activity, because zVAD and other used compounds are all potent inhibitors of caspases, while only zVAD is capable of priming (Figure 2). We find that inhibition of proteasome by its inhibitor, MG132 leads to an increase of MEF2C protein (Figure 3), indicating that proteasome activity could be the main factor involved in the modification of MEF2C protein stability. It is possible that $\mathrm{zVAD}$ may also regulate proteasome activity besides its inhibitory effect on caspases. It was reported that MG-132 prevents I $\mathrm{KB}$ degradation at very low concentrations [30]. The IC50 for inhibition of Suc-LLVY-AMC and Z-LLL-AMC cleaving activities of proteasome is 0.85 and $0.1 \mu \mathrm{M}$ respectively [31]. However, high doses of 40 or $50 \mu \mathrm{M}$ have also been used to ensure blockage of the degradation of IкB [32-34]. In our experiments, the MEF2C stabilization is observed only with high (50-100 $\mu \mathrm{g} / \mathrm{ml}$ ) but not with lower concentrations of MG132 (data not shown). The range of the concentration used in our experiments has also been reported by others [35]. One possibility is that effective concentrations of MG132 are variable depending on the cell types. It could not be excluded that different concentrations of the proteasome inhibitor may produce side effects other than inhibiting proteasome activity alone. However, it is beyond the scope of this study.

Overexpression of a dominant negative form of MEF2C protects against cell death in primed macrophages (Figure 4). It suggests that MEF2C has a major role in AICD. We have also transfected RAW 264.7 cells with wild type MEF2C. We did not see a difference between transfected and non-transfected cells in terms of sensitivity to LPS-induced cell death (data not shown). It is possible that MEF2C by itself is not sufficient to convert RAW 264.7 cells to the AICD-susceptible state. Kim et al has demonstrated that LPS induced apoptosis in zVAD primed macrophage requires Nur77 [22]. Although Nur77 induction requires the MEF family, either LPS or zVAD alone is not sufficient to induce the expression of Nur77 [22]. They also showed that zVAD induces MEF2A, C and $\mathrm{D}$ protein levels by blocking their degradation, which is 
consistent with our result that MEF2C level is increased in the presence of the proteasome inhibitor MG-132 (Figure 3 ). Our results suggest that $\mathrm{MEF} 2 \mathrm{C}$ is required to mediate macrophage AICD. However, it is not sufficient to induce macrophage AICD by itself. The molecular mechanism of AICD in zVAD primed macrophages has been well studied by Kim et al. [22]. They demonstrate that dual signaling pathways are involved in macrophage AICD. However, as zVAD is not a pathological stimulus, the relevance of their cell death model to in vivo situations remains to be determined. Here we have used several priming agents including $S$. typh, Ad5 and IFN- $\gamma$, which all represent bona fide pathologic components. Our data suggest that LPSinduced cell death in macrophages primed by pathologic agents and by the artificial agent zVAD may share similar mechanisms, and that the stability of MEF2C plays a key role in macrophage AICD.

\section{Acknowledgement}

This work was supported by a grant (No. 30330260) from National Natural Science Foundation of China.

\section{References}

1 Hegyi L, Hardwick SJ, Siow RC, Skepper, JN. Macrophage death and the role of apoptosis in human atherosclerosis. J Hematother Stem Cell Res 2001; 10:27-42.

2 Lan HY, Mitsuhashi H, Ng YY, et al. Macrophage apoptosis in rat crescentic glomerulonephritis. Am. J. Pathol. 1997; 151:531538.

3 Vignola AM., Chanez P, Chiappara G, et al. Evaluation of apoptosis of eosinophils, macrophages, and $\mathrm{T}$ lymphocytes in mucosal biopsy specimens of patients with asthma and chronic bronchitis. J Allergy Clin Immunol 1999; 103:563-573.

4 Placido R, Mancino G, Amendola A, et al. Apoptosis of human monocytes/macrophages in Mycobacterium tuberculosis infection. J Pathol 1997; 181:31-38.

5 Santucci MB, Amicosante M, Cicconi R, et al. Mycobacterium tuberculosis-Induced Apoptosis in Monocytes/Macrophages: Early Membrane Modifications and Intracellular Mycobacterial Viability. J Infect Dis 2000; 181:1506-1509.

6 Munn DH, Beall AC, Song D, Wrenn RW, Throckmorton DC. Activation-induced apoptosis in human macrophages: developmental regulation of a novel cell death pathway by macrophage colony-stimulating factor and interferon gamma. J Exp Med 1995; 181:127-136.

7 Janssen O, Sanzenbacher R, Kabelitz D. Regulation of activation-induced cell death of mature T-lymphocyte populations. Cell Tissue Res 2000; 301:85-99.

8 Donjerkovic D, Scott DW. Activation-induced cell death in B lymphocytes. Cell Res 2000; 10:179-192.

9 Haruta I, Kato Y, Hashimoto E, et al. Association of AIM, a novel apoptosis inhibitory factor, with hepatitis via supporting macrophage survival and enhancing phagocytotic function of macrophages. J Biol Chem 2001; 276:22910-22914.

10 Garaci E, Caroleo MC, Aloe L, et al. Nerve growth factor is an autocrine factor essential for the survival of macrophages infected with HIV. Proc Natl Acad Sci U S A 1999; 96:14013-14018.

11 Chen Y, Smith MR, Thirumalai K, Zychlinsky A. A bacterial invasin induces macrophage apoptosis by binding directly to ICE. EMBO J 1996; 15:3853-3860.

12 Hilbi H, Moss JE, Hersh D, et al. Shigella-induced apoptosis is dependent on caspase-1 which binds to IpaB. J Biol Chem 1998; 273:32895-32900.

13 Orth $\mathrm{K}, \mathrm{Xu} \mathrm{Z}$, Mudgett MB, et al. Disruption of signaling by Yersinia effector YopJ, a ubiquitin-like protein protease. Science 2000; 290:1594-1597.

14 Fratazzi C, Arbeit RD, Carini C, et al. Macrophage apoptosis in mycobacterial infections. J Leukoc Biol 1999; 66:763-764.

15 Perler L, Schweizer M, Jungi TW, Peterhans E. Bovine viral diarrhoea virus and bovine herpesvirus-1 prime uninfected macrophages for lipopolysaccharide-triggered apoptosis by interferon-dependent and -independent pathways. J Gen Virol 2000; 81:881-887.

16 Jungi TW, Schweizer M, Perler L, Peterhans E. Supernatants of virus-infected macrophages prime uninfected macrophages for lipopolysaccharide-induced apoptosis by both an interferondependent and an independent mechanism. Pathobiol 1999; 67:294-297.

17 Adler B, Adler H, Jungi TW, Peterhans E. Interferon-alpha primes macrophages for lipopolysaccharide-induced apoptosis. Biochem. Biophys. Res Commun 1995; 215:921-927.

18 Munn DH, Beall AC, Song D, Wrenn RW, Throckmorton DC. Activation-induced apoptosis in human macrophages: developmental regulation of a novel cell death pathway by macrophage colony-stimulating factor and interferon gamma. J Exp Med 1995; 181:127-136.

19 Lewis DB, Wilson CB. Gamma-interferon: an immunoregulatory lymphokine with immunotherapeutic potential. Pediatr Infect Dis J 1990; 9:642-651.

20 Sarih M, Souvannavong V, Adam A. Nitric oxide synthase induces macrophage death by apoptosis. Biochem Biophys Res Commun 1993; 191:503-508.

21 Ruckdeschel K, Mannel O, Richter K, et al. Yersinia outer protein $\mathrm{P}$ of Yersinia enterocolitica simultaneously blocks the nuclear factor-kappaB pathway and exploits lipopolysaccharide signaling to trigger apoptosis in macrophages. J Immunol 2001; 166:1823-1831.

22 Kim SO, Ono K, Tobias PS, Han J. Orphan nuclear receptor Nur77 is involved in caspase-independent macrophage cell death. J Exp Med 2003; 197:1441-1452.

23 Kravchenko VV, Pan Z, Han J, et al. Platelet-activating factor induces NF-kappa B activation through a G protein-coupled pathway. J Biol Chem 1995; 270:14928-14934.

24 Han J, Jiang Y, Li Z, Kravchenko VV, Ulevitch RJ. Activation of the transcription factor MEF2C by the MAP kinase p38 in inflammation. Nature 1997; 386:296-299.

25 Molkentin JD, Black BL, Martin JF, Olson EN. Cooperative activation of muscle gene expression by MEF2 and myogenic bHLH proteins. Cell 1995; 83:1125-1136.

26 Naya FS, Olson E. MEF2: a transcriptional target for signaling pathways controlling skeletal muscle growth and differentiation. Curr Opin Cell Biol 1999; 11:683-688. 
27 Leifer D, Krainc D, Yu Y, et al. MEF2C, a MADS/MEF2-Family Transcription Factor Expressed in a Laminar Distribution in Cerebral Cortex. Pro Nat Aca Sci 1993; 90:1546-1550.

28 Okamoto S, Krainc D, Sherman K, Lipton SA. Antiapoptotic role of the p38 mitogen-activated protein kinase-myocyte enhancer factor 2 transcription factor pathway during neuronal differentiation. Proc Natl Acad Sci U S A 2000; 97:7561-7566.

29 Okamoto S, Li Z, Ju C, et al. Dominant-interfering forms of MEF2 generated by caspase cleavage contribute to NMDAinduced neuronal apoptosis. Proc Natl Acad Sci U S A 2002; 99:3974-3979.

30 Fiedler MA, Wernke-Dollries K, Stark JM. Inhibition of TNFalpha-induced NF-kappaB activation and IL-8 release in A549 cells with the proteasome inhibitor MG-132. Am J Respir Cell Mol Biol 1998; 19:259-268.

31 Tsubuki S, Saito Y, Tomioka M, Ito H, Kawashima S. Differential inhibition of calpain and proteasome activities by peptidyl aldehydes of di-leucine and tri-leucine. J Biochem [Tokyo] 1996; 119:572-576.

32 Frost RA, Nystrom GJ, Lang CH. Lipopolysaccharide and proinflammatory cytokines stimulate interleukin-6 expression in $\mathrm{C} 2 \mathrm{C} 12$ myoblasts: role of the Jun NH2-terminal kinase. Am J Physiol Regul Integr Comp Physiol 2003; 285:1153-1164.

33 Clifton DR, Goss RA, Sahni SK, et al. NF-кB-dependent inhibition of apoptosis is essential for host cell survival during Rickettsia rickettsii infection. Proc Natl Acad Sci U S A 1998; 95:4646-4651.

34 Russell JS, Tofilon PJ. Radiation-induced Activation of Nuclear Factor- $\kappa B$ Involves Selective Degradation of Plasma Membraneassociated IкB $\alpha$. Mol Biol Cell 2002; 13:3431-3440.

35 Kim S, Ponka P. Nitrogen monoxide-mediated control of ferritin synthesis: implications for macrophage iron homeostasis. Proc Natl Acad Sci U S A 2002; 99:12214-12219.

Edited by Zhong Cheng Zheng 